\title{
De corpos e de santos: saúde mental, clínica e arte em uma videoinstalação*1
}

Este trabalho pretende descrever e analisar certos aspectos que envolveram uma obra de videoinstalação realizada por dois artistas em colaboração com usuários de saúde mental no Rio de Janeiro. O autor traz para análise alguns assuntos privilegiados, em correlação com a clínica: a fragmentação e a reintegração na psicose, o uso de imagens e seu retorno para a clientela participante, o papel do público para a amplificação da função de testemunho, o problema da autoria nesse contexto.

Palavras-chave: Arte, saúde mental, psicanálise, imagem

*1 Trabalho vinculado ao Núcleo de Estudos em Psicanálise e Clínica da Contemporaneidade, NEPECC.

${ }^{* 2}$ Universidade Federal do Rio de Janeiro - UFRJ (Rio de Janeiro, RJ, Br). 
Em 2012 foi aberta na coleção Prinzhorn, situada no Instituto de Psiquiatria da Universidade de Heildelberg (http://prinzhorn. ukl-hd.de/index.php?id=84), a visitação de Corpo Santo, de Dias \& Riedweg (Dias \& Riedweg, 2012). Trata-se de uma obra, em formato de videoinstalação, que contou com a participação de usuários de saúde mental do Rio de Janeiro. O objetivo deste artigo é descrever, discutir e propor uma breve análise sobre este encontro particular entre a arte e a experiência do sofrimento psíquico e de seu cuidado. Ao contrário de outros artigos, a trama conceitual aqui explicitada não constitui a sua linha de força principal. Só me sentirei à altura de discutir sobre o encontro entre uma dupla de artistas, o campo da saúde mental, a instituição psiquiátrica e sujeitos considerados psicóticos, se o fizer a partir do meu próprio ponto de vista e de afetação. Para tal é preciso suportar simplesmente escrever. Somente depois desse percurso, procurarei conceitos úteis para a compreensão de alguns de seus aspectos. Advirto, desde já, àqueles leitores versados em textos de crítica de arte - especialmente a arte contemporânea - que o lugar da obra examinada no universo artístico não será tema de meu interesse. Procurarei, tão somente, alcançar alguns aspectos de interseção deste trabalho com a prática clínica, os quais possam interessar ao campo da saúde mental.

\section{Estranhamento}

Este subtítulo, para alguém versado em psicanálise, traz à memória o famoso texto de Freud de 1919 "O estranho" (Freud 1919/1995b). Sem dúvida, o estranho familiar de que falava o autor, constitutivo de nossa divisão como sujeitos, é um aspecto presente 


\section{ARTIGOS}

naquilo que será relatado. Utilizo, entretanto, a noção de estranhamento de modo mais indeterminado. Certo dia do primeiro semestre de 2011, uma dupla de artistas procurou a direção de um hospital psiquiátrico do Rio de Janeiro porque estavam interessados em realizar uma obra de videoinstalação para a coleção Prinzhorn do Instituto de Psiquiatria de Heildelberg. Ao chegar, fui informado de que eles trabalhavam com projetos participativos o que, no presente caso, significaria um trabalho envolvendo pacientes. Eles ofereciam a sua disponibilidade e sua expertise para nos encontrar. Encontrar o desconhecido, o sem medida, o sem organização, o sem fala, o sem corpo. A frase anterior está toda sob a égide da escassez, porque este costuma ser o primeiro impacto do contato com essa forma particular de estranhamento. Eles pediam para nos encontrar exatamente onde não queremos ser encontrados. E logo também pareceram assustados com a ousadia desse pedido. Aquilataram que trabalhos pretéritos em presídios, em comunidades empobrecidas, ou com sujeitos das mais diferentes culturas, ${ }^{1}$ não constituía um guia seguro para o que eles encontrariam em nossa instituição. Participar de uma assembleia com pacientes, na qual o maior desafio é fazer as pessoas falarem umas com as outras, conversar com indivíduos - a palavra indivíduo neste contexto é puro hábito - que não conseguiam nos fazer reconhecer na frase seguinte algo que tinham dito na frase anterior, ver pessoas que não chegavam sequer a pronunciar uma sentença ou mover plasticamente seus corpos, esbarrar (literalmente) com aqueles que não conseguem parar de se mover e de falar, ouvir testemunhos de experiências inusitadas, ditas com certeza inabalável, envolvendo a perseguição sofrida por entidades incorpóreas, produziu uma espécie de perplexidade, a qual poderia ter dado fim a essa parceria recém-começada. Era um momento no qual este outro com quem se travaria contato era maciçamente captado em sua negatividade diferencial.

Nenhum conceito ou enquadramento conhecido poderia me auxiliar na tarefa de apresentar usuários e instituição para os artistas. Eles não estavam interessados apenas em conhecer, mas também em criar. Não buscavam somente saber - embora tivessem muita disponibilidade para tal — quem aquelas pessoas eram, mas sobretudo imaginar quem elas poderiam se tornar, mesmo que por apenas alguns instantes. Não se detinham se havia portões, horários, sujeira e caos. Queriam ser um veículo para que mensagens jamais

${ }^{1}$ Estes são alguns dos contextos nos quais Dias \& Riedweg realizaram muitos de seus trabalhos.

Rev. Latinoam. Psicopat. Fund., São Paulo, 20(1), 81-96, mar. 2017 


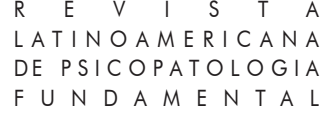

construídas pudessem ser endereçadas a qualquer um que se dispusesse a examiná-las. Quanto a mim, o que eles me pediam? O que a insistência obstinada de todos nós em seguir em frente solicitava? Eu deveria atender ao mandamento ético: ESTRANHE! A construção de um estranhamento singular e comum de tudo o que parecia velho, foi a marca dessa experiência. Usar o estranhamento em vez de sucumbir diante dele.

\section{Qorpo Santo}

Após uma rápida visita à instituição, adentramos em um local naquele momento abandonado. Fora, anteriormente, um belo teatro tombado, cujo nome, Qorpo Santo, servia de homenagem a um dramaturgo gaúcho do século XIX acometido pela loucura ainda no frescor de sua extensa obra, a qual assinava com esse nome peculiar (Lima, 2003). Lá, onde eu via escombros, eles enxergaram possibilidades. Onde eu via passado, eles enxergaram o futuro.

84 No final desse mesmo dia recebi um telefonema informando da convicção dos dois em realizar a obra no teatro. A direção da instituição deu todo o apoio necessário, inclusive em etapas que pareciam marcadas pelo impasse. Pouco tempo depois o esboço central da obra estava desenhado. Em suma, após um período de oficinas cujas finalidades seriam a ambientação à situação de grupo e a criação de vínculo com a equipe de artistas e do hospital, seriam confeccionadas 30 fantasias inspiradas em quadros da coleção Prinzhorn. Dentro de um ambiente teatral em escombros, cujo centro de gravidade seria uma grande penteadeira de teatro, ela mesma inspirada numa obra da coleção alemã, os usuários livremente escolheriam uma fantasia e criariam uma cena. Tudo a ser encenado seria escolhido e criado por eles.

\section{Imagens}

Apesar do entusiasmo com a proposta, um aspecto ainda precisaria ser ultrapassado. Tratava-se de uma videoinstalação e, portanto, a concessão de direito de imagem por parte dos usuários seria um pré-requisito para sua realização. Mesmo com o aval da direção após a aprovação do projeto pelo Comitê de Ética Médica e nenhuma objeção explícita por parte do corpo 


\section{ARTIGOS}

assistencial da instituição durante toda a execução da obra, deveríamos lidar com dois preconceitos no que tange à relação entre o usuário de saúde mental e sua imagem.

O primeiro é inespecífico e diz respeito à possibilidade dessas pessoas se responsabilizarem por suas decisões. Apesar da grande maioria delas ter sua capacidade civil garantida por lei, supõe-se muito facilmente que pela fragilidade de seus estados psíquicos, elas não sabem decidir e alguém deve fazê-lo em seus lugares. No caso da cessão de direito de imagem, é evidente que devemos levar em conta a singularidade de cada um e garantir que as condições mais propícias à decisão tenham sido construídas. Isto é uma norma que rege todo o cuidado a sujeitos com transtornos mentais graves e persistentes. Deveríamos empoderar esses sujeitos para que eles pudessem decidir sobre sua participação, mas não os barraríamos de antemão, baseados em critérios de exclusão predeterminados. Os elementos com que contaríamos para tal seriam: convite amplo a todos os usuários da instituição, portas de entrada e de saída permanentemente abertas, esclarecimento repetido à exaustão sobre a natureza do trabalho e sobre suas consequências, contatos frequentes com as equipes clínicas do hospital sobre possível contraindicação da participação de algum usuário em especial, comunicações às famílias sempre que houvesse viabilidade para isso e a avaliação da forma de adesão desses sujeitos ao projeto. Tecerei breve comentário sobre o último aspecto. Essas pessoas sobre as quais a lente da câmera incidiu apresentavam enorme dificuldade de se vincularem a atividades diferentes dos hábitos humanos de comer, dormir, fumar, caminhar, tomar remédios, conversar em ritmo variado, se agitar, brigar, fugir... e, last but not least, se tratar. Algo inusitado ocorreu já nas primeiras oficinas no teatro Qorpo Santo. Eles responderam prontamente ao convite. Mais de 50 usuários de vários serviços compuseram o elenco da videoinstalação Corpo Santo, apresentada no ano seguinte em Heildelberg. Quem está familiarizado com o trabalho em saúde mental, sabe perfeitamente que não há melhor critério de decisão para essa clientela do que uma adesão tão intensa. Não custa lembrar que a participação da grande maioria durou meses e não foi restrita a uma efeméride.

O segundo obstáculo é mais específico. Supõe-se que a experiência de ter sua imagem captada por uma câmera manipulada por outro ser humano possa intensificar sintomas paranoides em pessoas predispostas, como costumam ser alguns dos usuários de saúde mental. Para examinar esta hipótese tentarei descrever o que acontece quando sujeitos com outra organização psíquica se deparam com a visão de suas próprias imagens. 
Darei meu próprio exemplo. Sinto enorme desconforto ao ver vídeos em que apareço. Ver-me de fora pode ser assustador para mim. Mesmo quando são registros de momentos prazerosos, sinto-me subtraído da representação que construí para ser inundado por imagens captadas por outrem. Percebam bem, o meu desconforto está intimamente ligado à minha adesão a imagens mais ou menos delimitadas de mim mesmo, algumas delas ideais, das quais não quero me desapegar. No vocabulário psicanalítico, referimos fatos como esses ao campo do narcisismo (Freud 1914/1995a). A subordinação a uma imagem, que supomos nossa, a qual nos aliena, nos fixa e nos amarra, pode ser um dos grandes obstáculos a transformações psíquicas que aumentem nosso grau de liberdade ao preço de nossa segurança.

Dito isto, tentemos nos aproximar do que pode ser a vivência de um participante do elenco de Corpo Santo quanto a esse aspecto. Ao contrário de mim, pelos mais diferentes motivos, a maioria deles encontra dificuldade para construir imagens estáveis de si. Já ouvi da boca de um deles: "o mundo é iluminado por uma luz estroboscópica. Liga e apaga sem parar". No momento em que apaga, o mesmo tem a sensação de que desaparece. Supomos que o desaparecimento é constitutivo de sua imagem e recuperar repetidamente a luz 86 é um desafio vital. Aqui não há excesso de imagens a se imbricarem umas nas outras, culminando em algum tipo de reconhecimento. Eles devem realizar um esforço permanente a fim de se reconhecerem.

Ora, neste contexto o que pode representar para eles as imagens captadas por uma câmera operada por um outro? Esta pergunta não pode ser respondida genericamente. Depende da relação com esse outro. Uma tríade surge no horizonte: liberdade, confiança e um jogo favorável de proximidade e distância. É preciso criar um ambiente no qual haja múltiplas alternativas, onde exista escolha entre diferentes modalidades de ação. Na relação que estabelece com a câmera, com quem a opera, com o grupo, com a atmosfera do teatro, com o possível espectador, com as fantasias e com a própria cena, o sujeito deve sentir que as imagens resultantes de tudo isso, serão fruto de uma escolha em contexto suficientemente livre. Em correlação com a possibilidade de escolha, cabe àqueles que sustentam o dispositivo proposto, criarem uma relação de confiança a partir da qual também farão suas escolhas em relação às imagens mais representativas do que foi construído em conjunto. A sensibilidade do artista é sua principal ferramenta, já que ele deve encontrar um ponto de vista nem tão próximo a ponto de ser invasivo, nem tão distante a ponto de impedir o processo de reconhecimento por parte do sujeito portador da imagem. 


\section{ARTIGOS}

O exposto acima é uma leitura retrospectiva do que aconteceu nos anos de 2011 e 2012. Eu não tinha nada disso em mente quando simplesmente constatava a familiaridade dos participantes com as diversas câmeras presentes no teatro. Aprenderam a olhar através delas e chegavam a sugerir ângulos mais favoráveis. Participei de várias sessões em que fragmentos ainda em fase de edição ou o vídeo pronto foram mostrados para muitos dos atores e protagonistas da obra. A satisfação, e sobretudo o reconhecimento eram extravasados desde os modos mais sutis aos mais explícitos. Uma cena particularmente me tocou. Refere-se ao gesto de um sujeito que mal falava, quando suas mãos, apenas elas, surgiram na tela. Ele imediatamente as reconheceu e olhou em seguida para suas mãos fora da tela, para voltar a mirar o vídeo. Como eu estava sentado ao seu lado, tive a nítida sensação de que aquela era uma experiência nova na qual seu corpo existia dentro dele e podia ser visto de fora, ao mesmo tempo. Suas mãos agora estavam articuladas a seu corpo. Ao contrário do que ocorre comigo, as imagens construídas segundo a tríade suposta produziram, para o elenco, um efeito de reconhecimento e não de terror. $\mathrm{O}$ ambiente construído pelos artistas foi decisivo para esse desfecho.

\section{Fragmentos}

Fragmentação é o termo aproximativo que damos à experiência de sujeitos que encontram barreiras intransponíveis na constituição de uma sensação mínima de unificação espacial, temporal, corporal e no agir. Fragmentar-se é uma forma de viver. Evidentemente, uma forma precária de viver. Corpo Santo é também um corpo fragmentado, mas um corpo reconstruído ativamente através de fragmentos criados por um novo vínculo. Os artistas não exigiram dos usuários nenhuma coerência, ou linha de continuidade entre as cenas ou narrativas com intencionalidade clara. Nessa construção por fragmentos, a regularidade do espaço e da presença daqueles que o habitavam três vezes por semana, organizava os fragmentos numa lógica acessível a todos.

A ambientação de teatro com a presença sempre ruidosa da plateia transformou um mero espaço num lugar. Podemos evocar a noção de lugar (Oury, 2009) para apontar para um "onde" no qual a dimensão do desejo se expressa, lá exatamente onde antes não havia desejo algum. Cenas nas quais os atores simplesmente se fantasiam, se entrecruzam com outras em que se 


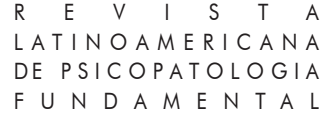

declama uma poesia ou se conta uma história ou se expressa um ponto de vista ou se cria uma cena mais elaborada de teatro ou se canta ou se entoa louvores, ou... ou... ou... O que dá coesão à obra, apesar do desconforto que ela pode provocar no espectador, é a atividade de encenar. É a empatia que sentimos com o tornar-se outro dos atores, lá exatamente onde o tornar-se é extremamente raro.

Há em Corpo Santo uma descontinuidade constitutiva, a aceitação de um modo de vida e de expressão que geralmente nos são alheios. Se a obra começa com o estranhamento, com o susto pela alteridade disruptiva, ela também evoca proximidade para com a humanidade do outro. Humanidade que resiste à fragmentação e ao alheamento, mas que subsiste justamente aí. $\mathrm{O}$ teatro, como lugar e como linguagem, mostrou-se uma ferramenta potente para encenar a fragmentação, não mais tomada como posse exclusiva do homem louco, mas como algo que nos dá origem e não nos abandona jamais. Encenando a fragmentação, possivelmente a suportaremos melhor.

\section{A obra}

A obra Corpo Santo foi aberta ao público na coleção Prinzhorn, em Heildelberg, em junho de 2012. Desde então já foi exposta em outros países europeus, tais como Suíça e Dinamarca. Não é um trabalho documental, não há um narrador a nos guiar na produção de um sentido, não há uma história a ser contada, não há personagens a serem construídos e decifrados de modo linear. Distância e proximidade se embaralham e pode haver mudanças no regime de alteridade.

Num grande salão, acrescido de um mezanino, estavam condensados materiais, obras e cenas que uniram 150 anos de história da relação singular entre a arte e a experiência do sofrimento mental. A exposição era composta por quatro elementos integrados. O centro da penteadeira, usada no teatro, foi ocupado por uma tela que exibia as cenas construídas pelo elenco. $\mathrm{Na}$ imensa parede ao fundo eram mostrados fragmentos do processo de criação. Estes eram intercalados com imagens das obras da coleção alemã referidas às cenas mostradas na penteadeira. Nas laterais do salão podiam ser vistas as trinta fantasias usadas pelo elenco, todas elas inspiradas na maior coleção de arte bruta do mundo. Nas paredes do mezanino, encontravam-se expostas as 30 obras originais que povoaram nosso imaginário - dos artistas, dos usuários, da equipe - em todo o processo: parte do acervo de 150 anos da 


\section{ARTIGOS}

coleção Prinzhorn, peças produzidas por internos do Instituto de Psiquiatria de Heildelberg ao longo de sua história, sobretudo no século XIX.

Percorrer os 80 minutos de projeção de Corpo Santo sem o público foi algo vertiginoso. Eu — assim como os membros do elenco e a equipe da instituição - não participei da edição da videoinstalação. A sensação de estar à mercê do olhar do artista, daquilo que ele capta e interpreta, era, sem dúvida, desconfortável e angustiante. Tudo o que expus sobre o reconhecimento dos usuários só foi posto à prova posteriormente, quando retornei, ou nas sessões de apresentação de pequenos fragmentos ainda em fase de pré-produção. Some-se a tudo isso o fato de estarmos na Alemanha, num serviço por onde passaram Jaspers, Kraepelin e tantos outros. Assim como o público que lotou o salão horas depois e aplaudiu vigorosamente o que viu, eu também, depois de respirar aliviado, expressei meu entusiasmo por algo que eu não compreendia inteiramente. Mas o que é se tornar parte do público neste caso? Qual é o papel do público numa obra como Corpo Santo? Será que o contato com o público é fundamental para essa obra e, mais especificamente, para o seu elenco e para a atividade clínica?

\section{O público}

Este é um tema pouco desenvolvido no campo da saúde mental. Quando pensamos na importância da arte como forma de expressão e como modalidade de criação, geralmente nos dirigimos para o processo artístico e seu produto. Que tipo de arte é aquela produzida num contexto psiquiatrizado (Lima \& Pal Pelbart, 2007; Lima, 2006; Ferraz, 1998; Teixeira Coelho, 2002)? Qual é a relação entre o trabalho artístico e o campo da terapêutica (Lima \& Pal Pelbart, 2007; Thomazzoni \& Fonseca, 2011; Liberato \& Dimenstein, 2013)? O que a arte pode nos ensinar sobre o sujeito e suas produções (Rivera, 2007)? Estas são algumas das inúmeras perguntas formuladas por diversos autores desde o trabalho pioneiro de Prinzhorn (1922/2003). Meu interesse, entretanto, é um pouco diverso. Para a obra aqui discutida, a necessidade de contato com o público encontra sua fonte apenas no interesse dos artistas que a assinam, ou, em acréscimo, ela é fundamental para os usuários participantes do projeto?

Teremos de retroceder na argumentação e discutir o que é o tornar-se, operador subjetivo que confere a Corpo Santo toda a sua potência. Apesar das generalizações serem sempre perigosas, há ampla literatura, tanto na 


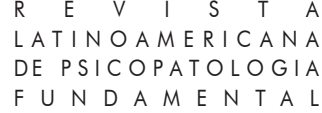

psiquiatria (Minkowski, 1933/1995) quanto na psicanálise (Winnicott, 1958/2000), acerca de problemas na experiência temporal usual entre sujeitos considerados psicóticos, imensa maioria desses usuários. Experiência temporal usual significa uma vivência pré-reflexiva de continuidade entre estados que, do ponto de vista neutro ou puramente objetivo, seriam descontínuos. É tal continuidade que permite a sensação de permanência quando a vida psíquica se torna outra e se transforma. Trata-se de uma articulação, de uma amarração, de um fluxo, para usar expressões habituais que a qualificam. $\mathrm{O}$ que está em jogo então no tornar-se é uma passagem. É o reconhecimento inconsciente do passado num tempo aberto e imprevisível. A continuidade subjetiva no tempo é o que nos permite suportar a imprevisibilidade, o descentramento e a indeterminação de nossa relação com o mundo.

Como afirmado antes, os transtornos apresentados por certos sujeitos na sua vivência pré-reflexiva de continuidade, podem torná-los "prisioneiros da passagem", título do filme de Hugo Denizart sobre Arthur Bispo do Rosário (Denizart, 1982). A passagem é sempre um risco, pois ela pode caracterizar-se por um tempo circular, quase um fora do tempo, no qual só se encontra coordenadas eficazes através de estruturas espaciais descontínuas ou da regularidade de um outro (geralmente ser humano) significativo. Este último, através de sua presença e de sua capacidade de refletir para o sujeito (Roussillon, 2008), algo que ele não pode apreender de outro modo, contribui para que haja efetivamente alguma forma de passagem. O tempo, desse modo, seria menos penoso e o sujeito poderia reconhecer algo de si quando já se tornou outro. Esta capacidade de reflexão do outro no que tange a fazer retornar para o sujeito, de forma suportável, suas produções, pode construir um lugar de testemunho, função primordial para o cuidado daqueles a quem consideramos psicóticos. O testemunho é o fiador do trabalho psíquico do sujeito. Ele atesta a verdade e a existência de um processo que pode finalmente encontrar seu lugar no mundo e naquilo que costumamos chamar de interioridade. A função de testemunho expande a experiência de uma vida partilhada num mundo suficientemente comum.

Apresento agora a hipótese de que o público de uma obra como Corpo Santo pode amplificar a função do testemunho. O contato com o público é a última etapa de uma cadeia que visa a ratificar a existência daquela experiência. O incômodo, muitas vezes vivido pelo espectador ao longo da projeção, refere-se ao fato de ele se sentir conectado ao estranhamento evocado pela obra. Ele é confrontado com algo difícil de localizar. Logo após as primeiras encenações, uma cortina imaginária se fecha e ouve-se o 


\section{ARTIGOS}

barulho de palmas. $\mathrm{O}$ espectador supõe que está diante de uma encenação com a presença de público. Cria-se uma conexão imediata, mas heterodoxa, entre dois públicos. Um público que participa do processo e sustenta a experiência do tornar-se numa realidade teatral, e outro público que, ao entrar em contato com a obra e vir a pertencer a um corpo de espectadores anônimos, torna-se também fiador daquela produção. Fiador não harmônico, diga-se de passagem. No caso do público anônimo, não é necessário gostar da obra, identificar-se com os personagens, conectar-se com a humanidade dos atores, para ocupar o lugar de testemunho. Como dissemos antes, Corpo Santo produz estranheza, pode evocar um jogo indefinido de proximidade e distância, nos faz entrar em contato com a fragilidade, a fragmentação e a dor, mas também tem humor, criatividade e capacidade de afetar. Todas essas, e por ventura outras características, ensejam uma reação no público, não importa qual seja, que amplia a função do testemunho. O vocábulo "público" nos faz entrever de qual tipo de testemunho se trata: o testemunho público. Ao contrário daqueles de quem escutamos as palmas no vídeo, não é preciso ter um vínculo privilegiado com os artistas, com os atores, com o hospital ou com o campo da saúde mental, para atestar que o exposto diante de seus olhos tem lugar no mundo. E mais ainda: é um produto humano. Faz parte do repertório demasiadamente humano de viver. Alcançar esse nível de testemunho pode ser importante para alguns sujeitos encontrarem direito de cidadania para os aspectos mais idiossincráticos desse repertório.

\section{Autoria}

Chegamos agora ao último ponto deste artigo. Como pensar a autoria num processo e num produto que envolveu a participação de tantos? Não pretendo discutir o tema, filosoficamente relevante, "o que é um autor?" Meu objetivo é simplesmente pensar em alguns efeitos da participação de usuários de saúde mental num trabalho artístico assinado por outro. Ao contrário de uma obra posterior - Nada, absolutamente nada (Dias \& Riedweg, 2015) - na qual houve uma colaboração formal entre um grupo mais organizado de usuários e esses mesmos artistas, em Corpo Santo, os usuários, individualmente, ganham lugar nos créditos como parte do elenco. O que é fazer parte de um elenco nesse contexto? Esta pergunta se articula a outras: que tipo de responsabilidade é esperada de um participante desse elenco e qual é sua relação com a obra como um todo? 


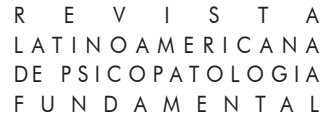

Um aspecto chamou particularmente a minha atenção em todas as apresentações da obra pronta para os usuários: a posição de conforto de cada um a respeito de seu próprio lugar. Ao contrário de Nada, absolutamente nada, a noção de pertencer a um grupo, em Corpo Santo, era fluida e móvel. Ela respeitava configurações efêmeras, que muitas vezes só ocorriam em determinado dia, sem se repetir. A participação de cada usuário era variável e estava conectada de modo potencial a todo o processo. Mesmo assim, foi construída aos poucos uma noção partilhada de responsabilidades e, nesta, a divisão entre as funções dos artistas, da equipe de suporte e do elenco se consolidou. $\mathrm{O}$ enquadramento concebido pelos artistas e trabalhado por toda a equipe, fez com que os atores pudessem assumir a responsabilidade pela criação e execução de suas cenas. Ser parte - mesmo que aparentemente fragmentada - ser reconhecido nessa conformação e ser exigido apenas desse lugar, definiu o estatuto de participante do elenco. Um grupo de semelhantes heterogêneos articulados entre si pelo olhar do artista.

Como pensar então o tema da autoria? Os autores da obra são aqueles capazes de se responsabilizar pelo todo que emerge do processo, desde o convite para sua realização até o produto final. A autoria instaura uma

92 assimetria constitutiva que sustentou um ponto de vista particular surgido desse encontro. Ponto de vista intransferível. A liberdade, a confiança e a justa distância deram segurança ao elenco para acreditar que a sua participação/ autoria nas cenas e fragmentos seriam reconhecidas na obra assinada pelos artistas. A assimetria instaurada pela autoria, em Corpo Santo, contribuiu diretamente para a integração paradoxal que essa videoinstalação reflete.

É importante notar que, até onde pude perceber, a assinatura da obra pelos artistas, definindo formalmente a autoria, não consistiu num processo de despossessão. Os usuários não se sentiram alijados de um lugar e de um papel que lhes caberia. Pelo contrário, dos modos mais diversos possíveis, expressaram que suas necessidades foram atendidas. Necessidade de assumirem a responsabilidade apenas pelo que se tornara possível a partir do convite para integrar a obra.

\section{Concluindo...}

Como se pode perceber, este artigo não se define como uma análise neutra e objetivamente distante da obra Corpo Santo, de Dias \& Riedweg. Ao contrário, acredito que o ponto de vista aqui expresso possa ser ferramenta 


\section{ARTIGOS}

valiosa para uma análise futura com estas características, realizada por quem tenha mais capacidade para tal do que eu. Meu objetivo com estas linhas é dar tão somente meu testemunho daquilo que pude experimentar e pensar num processo complexo, referido a um tema que ainda deve ser aprofundado no campo da saúde mental. Procurei, sobretudo, discutir essa videoinstalação tendo como parâmetro uma visada clínica. Afinal de contas, se a função de testemunho é especialmente valiosa no cuidado daqueles que sofrem, e superam diariamente o que nos acostumamos a denominar de transtornos mentais, o testemunho de um profissional do campo pode contribuir para a amplificação dessa função.

\section{Referências}

Denizart, H. (1982). O prisioneiro da passagem, filme, CNPI.

Dias, M., \& Riedweg, W. (2012). Corpo Santo. Videoinstalação. Heildelberg, Prinzhorn

Dias, M., \& Riedweg, W. (2015). Nada, absolutamente nada. Videoinstalação. Rio de Janeiro, RJ: Casa Daros.

Ferraz, M.H.C.T. (1998). Arte e loucura: limites do imprevisível. São Paulo, SP: Lemos Editorial.

Freud, S. (1995a). Sobre o narcismo: uma introdução. In Edição Standard Brasileira das Obras Psicológicas Completas de Sigmund Freud (Vol. XIV, pp. 89-122). Rio de Janeiro, RJ: Imago. (Trabalho original publicado em 1914).

Freud, S. (1995b). O estranho. In Edição Standard Brasileira das Obras Psicológicas Completas de Sigmund Freud (Vol. XVII, pp. 275-314). Rio de Janeiro, RJ: Imago. (Trabalho original publicado em 1919).

Liberato, M.T.C, \& Dimenstein, M (2013). Arte, loucura e cidade: a invenção de novos possíveis. Psicologia \& Sociedade, 25(2), 272-281.

Lima, E. M. F. A. (2003, abril/junho). A produção e a recepção dos escritos de QorpoSanto: apontando transformações nas relações entre arte e loucura. Interface: comunicação, saúde e educação, 14(33), 437-47.

Lima, E. M. F. A. (2006, julho/junho). Por uma arte menor: ressonâncias entre arte, clínica e loucura na contemporaneidade. Interface: comunicação, saúde e educação, 10(20), 317-29.

Lima, E. M. F. A., \& Pal Pelbart, P. (2007, julho/setembro). Arte, clínica e loucura: um território em mutação. História, ciência e saúde, 14(3), 709-735. 


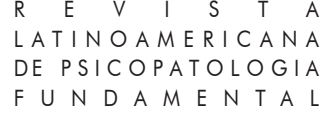

Minkowski, E. (1995). Le temps vécu. Étude phénoménologique et psychopathologique. Delachaux: PUF-Quadrige. (Trabalho original publicado em 1933).

Oury, J. (2009). O coletivo. São Paulo, SP: Hucitec.

Prinzhorn, H. (2003). Artistry of the mentally ill: a contribution to the psychology and psychopathology of configuration. Wien, New York: Springer-Verlag. (Trabalho original publicado em 1922).

Rivera, T. (2007, janeiro). O sujeito na psicanálise e na arte contemporânea. Psicologia Clínica, 19(1), 13-24.

Roussillon, R (2008). Le transitionnel, le sexuel et la reflexivité. Paris: Dunod.

Teixeira Coelho (2002), A arte não revela a verdade da loucura, a loucura não revela a verdade da arte. In E. H. Antunes, L. H. S. Barbosa, L. M. F. Pereira, Psiquiatria, loucura e arte: fragmentos da história brasileira (pp. 147-163). São Paulo, SP: Edusp.

Thomazonni, A. R., \& Fonseca, T. G. (2011, julho/dezembro). Encontros possíveis entre Arte, Loucura e Criação. Mental, IX(17), 605-620.

Winnicott, D. W. (2000). Da pediatria à psicanálise. Rio de Janeiro, RJ: Imago. (Trabalho original publicado em 1958).

\section{Resumos}

(On bodies and saints: mental and clinical health and art in a video installation)

This paper aims to describe and analyze certain aspects that concern the creation of a video installation by two artists in collaboration with mental health service users in Rio de Janeiro, Brazil. The author highlights certain privileged issues regarding clinical practices: fragmentation and reintegration in psychosis, the use of images and their returns for participating customers, the role of the public for the expansion of the witness function, and the problem of authorship in this context.

Keywords: Art, mental health, psychoanalysis, image

(Des corps et des saints: santé mentale, clinique et art dans une installation vidéo)

Cet article vise à décrire et à analyser certains aspects concernant une installation vidéo réalisée par deux artistes en collaboration avec des patients du domaine de la santé mentale à Rio de Janeiro. L'auteur analyse certaines questions en corrélation avec la clinique: la fragmentation et la réinsertion dans la psychose, l'utilisation d'images et 


\section{ARTIGOS}

son retour aux participants, le rôle du public en ce qui concerne l'amplification de la fonction de témoin, ainsi que le problème de la titularité dans ce contexte.

Mot clés: Art, santé mentale, psychanalyse, image

(De cuerpos y de santos: arte, clínica y salud mental en una videoinstalación)

Este trabajo pretende describir y analizar algunos aspectos involucrados en una obra de videoinstalación, realizada por dos artistas en colaboración con usuarios de salud mental en Río de Janeiro. El autor analiza algunos temas privilegiados en correlación con la clínica: la fragmentación y la reintegración en la psicosis, el uso de imágenes y su retorno a los clientes participantes, el papel del público en la amplificación de la función de testigo y el problema de la autoría en ese contexto.

Palabras clave: Arte, salud mental, psicoanálisis, imagen

(Von Körpern und Heiligen: Psychische Verfassung, Klinik und Kunst in einer Videoinstallation)

Dieser Beitrag beschreibt und analysiert ausgewählte Aspekte einer Videoinstallation zweier brasilianischer Künstler welche im Rahmen einer Kooperation mit geistig behinderten Patienten durchgeführt wurde. Der Autor behandelt in diesem Zusammenhang die folgenden Themen: die Zerstückelung und Reintegration in der Psychose, der Gebrauch von Bildern und seinen Nutzen für die Patienten, die Rolle des Publikums zur Verstärkung der Funktion des Zeugens, das Problem der Autorschaft.

Schlüsselwörter: Kunst, psychische Gesundheit, Psychoanalyse, Bildern

(从肉身到圣徒：精神健康、临床与艺术的融合）

本文通过一段由里约热内卢的两位艺术家和精神病人共同录制完成的视 频，针对精神问题展开分析。笔者讨论了本次临床实践带来的相关的议题：精 神的碎片化与再整合，影像资料的应用及其给参与录制者带来的回报，公众的 见证人的角色，病人作为作者而产生的问题。

关键词：艺术，精神健康，心理分析，图像。

Citação/Citation: Verztman, J. (2017, março). De corpos e de santos: saúde mental, clínica e arte em uma videoinstalação. Revista Latinoamericana de Psicopatologia Fundamental, 20(1), 81-96

Editores do artigo/Editors: Profa. Dra. Ana Maria Rudge Profa. Dra. Sonia Leite

Recebido/Received: 10.8.2016/ 8.10.2016 Aceito/Accepted: 19.10.2016 / 10.19.2016

Rev. Latinoam. Psicopat. Fund., São Paulo, $20(1), 81-96$, mar. 2017 


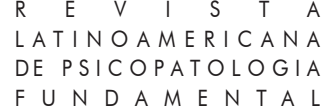

Copyright: (C) 2009 Associação Universitária de Pesquisa em Psicopatologia Fundamental/ University Association for Research in Fundamental Psychopathology. Este é um artigo de livre acesso, que permite uso irrestrito, distribuição e reprodução em qualquer meio, desde que o autor e a fonte sejam citados / This is an open-access article, which permits unrestricted use, distribution, and reproduction in any medium, provided the original authors and sources are credited.

Financiamento/Funding: $\mathrm{O}$ autor declara não ter sido financiado ou apoiado / The author has no support or funding to report.

Conflito de interesses/Conflict of interest: $\mathrm{O}$ autor declara que não há conflito de interesses / The author has no conflict of interest to declare.

\section{Julio Verztman}

Doutor em ciências da saúde pela Universidade Federal do Rio de Janeiro - UFRJ (Rio de Janeiro, RJ, Br)); Professor do programa de pós-graduação em teoria psicanalítica (PPGTP-UFRJ) e professor do programa de mestrado profissional em atenção psicossocial (IPUB-UFRJ); Coordenador do NEPECC; Psiquiatra do IPUB-UFRJ.

Rua Davi Campista, 105 - Humaitá

22261-010 Rio de Janeiro, RJ, Br

jverztman@globo.com the original authors and sources are credited. 